\title{
PENGARUH LEADER MEMBER EXCHANGE (LMX) TERHADAP ORGANIZATIONAL CITIZENSHIP BEHAVIOR (OCB) PERAWAT SUKU BUGIS-MAKASSAR INSTALASI RAWAT INAP RSUD LABUANG BAJI
}

\author{
THE INFLUENCE OF LEADER MEMBER EXCHANGE (LMX) \\ ORGANIZATIONAL CITIZENSHIP BEHAVIOR(OCB) NURSES OF BUGIS- \\ MAKASSAR TRIBE IN INPATIENT INSTALLATION OF LABUANG BAJI \\ HOSPITAL
}

\author{
Rifa'ah Mahmudah', Andi Indahwaty², Yahya Thamrin ${ }^{3}$ \\ ${ }^{1}$ Manajemen Administrasi Rumah Sakit, Fakultas Kesehatan Masyarakat,Universitas Hasanuddin \\ 2Manajemen Administrasi Rumah Sakit, Fakultas Kesehatan Masyarakat,Universitas Hasanuddin \\ ${ }^{3}$ Bagian Kesehatan dan Keselamatan Kerja, Universtitas Hasanuddin, Makassar \\ Email Korespondensi: rifaahmahmudah24@gmail.com
}

\begin{abstract}
ABSTRAK
Nilai budaya diperoleh seseorang dari awal kehidupan yang mempengaruhi perilaku di tempat kerja. Leader Member Exchange yang tinggi telah diketahui dapat memotivasi karyawan sehingga dapat menunjukkan perilaku Organizational Citizenship Behavior yang dipercaya menjadi penyebab meiningkatnya produktifitas di tempat kerja. Penelitian ini bertujuan untuk menganalisis pengaruh leader member exchange terhadap organizational citizenship behavior Perawat Suku Bugis-Makassar di Instalasi Rawat Inap RSUD Labuang Baji. Penelitian ini merupakan penelitian kuantitatif. Rancangan yang digunakan adalah observasional analitik dengan pendekatan cross-sectional study. Sampel sebanyak 98 orang perawat dipilih dengan teknik purposive sampling dengan kriteria suku BugisMakassar. Data dianalisis dengan menggunakan uji regresi linear berganda. Hasil penelitian responden dengan karakter Bugis-makassar yang erat dengan nilai budaya siri' na pacce dengan kriteria sipakatau (kemanusiaan); deceng (baik); asseddingeng (kesatuan) dan marenreng perru (setia) menunjukkan bahwa ada pengaruh signifikan proffesional respect $(\mathrm{p}<0,05)$, contribution ( $\mathrm{p}<0,05)$, dan affect $(\mathrm{p}<0,05)$ terhadap organizational citizenship behavior. Sebaliknya, tidak ada pengaruh loyalty $(\mathrm{p}>0,05)$ terhadap organizatioonal citizenship behavior perawat Suku Bugis Makassar
\end{abstract}

Kata Kunci : Leader Member Exchange, Organizational Citizenship Behavior; Bugis-Makassar

\begin{abstract}
Cultural value is obtained by anyone from the beginning of life that influences workplace behavior. Leader Member Exchange at high level have been known to motivate employees so they can demonstrate Organizational Citizenship Behavior that is believed to be determinant factor cause of increasing productivity in the workplace. This study aims to analyze the influence of leader member exchange on organizational citizenship behavior nurses of the Bugis-Makassar tribe in the inpatient installation of Labuang Baji Hospital. This research is quantitative research. The design used was analytic observational with a cross-sectional study approach. A sample of 98 nurses were selected by purposive sampling technique with the Bugis-Makassar tribe criteria. Data were analyzed using multiple linear regression tests. The result of the respondents with Bugis-makassar characters are closely related to the cultural values siri na pacce with the criteria of sipakatau (humanity); deceng (goodness); asseddingeng (unity); and marenreng perru (loyal) showed that there was significant influences of proffesional respect $(p<0,05)$, contribution $(p<0,05)$, and affect $(p<0,05)$ on organizational citizenship behavior. On the contrary, there was no influence of loyalty $(p>0,05)$ on the organizational of citizenship behavior of Bugis-Makassar tribe
\end{abstract}

Keywords: Leader Member Exchange, Organizational Citizenship Behavior; Bugis-Makassar. 


\section{PENDAHULUAN}

\section{Organizational citizenship behavior} $(O C B)$ merupakan sebuah konsep yang diperkenalkan pertama kali oleh Smith (1983), dasar konsep OCB adalah konsep perilaku organisasi oleh Katz (1964) yang dikenal sebagai perilaku extra role (Smith dkk., 1983). OCB merupakan perilaku positif dari karyawan, organisasi yang aktif dan tidak aktif dapat dibedakan dari kualitas karyawannya, karyawan dengan OCB memiliki perilaku sukarela, senang menolong, memiliki upaya yang efektif dalam bekerja (Taghinezhad dkk., 2015). Munculnya perilaku OCB dipengaruhi oleh faktor yang beragam meliputi karakteristik dari individu yang berbeda, variasi sikap atau persepsi (kepuasan kerja, komitmen organisasi dan persepsi keadilan), faktor kepemimpinan (transformational dan transactional serta LMX) dan karakteristik pekerjaan (task feedback dan task interpendence) (Podsakoff dkk., 2000).

Beberapa penelitian menyatakan bahwa kepemimpinan memiliki pengaruh yang paling besar kepada perilaku staff yang bekerja dalam sebuah organsasi, interaksi antara hubungan atasan dan bawahan menjadi hal yang sangat penting dalam kepemimpinan karena berdampak pada perilaku staff yang akan berpengaruh pada kinerja dan mengarah pada efektifitas organisasi (Robbins, 2013). Interaksi antara atasan dan bawahan dikenal dengan teori leader member exchange (LMX) (Anand dkk., 2017).

Konsep LMX masih sedikit diteliti dari awal tahun berkembangnya yaitu tahun 1975 hingga saat ini, selain itu LMX adalah satu-satunya teori kepemimpinan yang melihat pada "hubungan" (Erdogan, 2015). Gooty (2013) mengatakan bahwa apabila interaksi atasan-bawahan berkualitas tinggi maka seorang atasan akan berpandangan positif terhadap bawahannya dan bawahan akan memperlihatkan kinerja yang lebih baik sebagaimana mereka dimotivasi untuk berusaha lebih keras dalam melaksanakan tugas mereka yang dapat berpengaruh terhadap kinerja organisasi dan OCB yang lebih baik (Gooty dkk., 2013; Anand, dkk., 2017).

RSUD Labuang Baji Makassar merupakan rumah sakit kelas B milik Pemerintah Daerah Sulawesi Selatan. Rumah sakit ini sebagai salah satu rumah sakit rujukan bagi masyarakat kabupaten/kota di provinsi Sulawesi Selatan, sehingga ditutuntut untuk memiliki kinerja pelayanan yang maksimal. Selain karena masyarakat Sulawesi-Selatan yang kebanyakan bersuku Bugis-Makassar memiliki karakter sikap saling menghargai, saling membantu satu 
sama lain, sikap mempercayai serta melakukan perbuatan yang sesuai dengan yang dikatakan yang menuntutnya untuk memberikan pelayanan yang terbaik (Amin dkk., 2015).

Nilai budaya di Sulawesi-Selatan oleh masyarakat Bugis-Makassar yang dikenal berani mengambil resiko, ulet dan percaya diri dikenal dengan istilah sirik na passe yang dijadikan sebagai pegangan hidup turuntemurun dan mempengaruhi sikap, perilaku dan tingkah laku masyarakat Bugis-Makassar (Omar dkk., 2017), dalam siri' na pesse terdapat beberapa nilai yang merujuk pada peningkatan kinerja dalam organisasi misalnya matinulu (kerja keras) yaitu sebuah karakter yang akan bekerja keras untuk mencapai tujuan, getteng (teguh) yaitu karakter yang kokoh memegang pendirian serta tidak akan goyah jika diberi amanat, macca (cerdas), deceng (baik), assidengeng (kesatuan), marenreng perru (setia), sipakatau (kemanusiaan), dengan prinsip ini diharapkan individu dengan suku BugisMakassar dapat memiliki kinerja yang mendukung dalam pemberian pelayanan berkualitas (Amin dkk., 2015). Sebab organisasi tidak dapat mengabaikan budaya atau suku/etnik kelompok dalam pengaruhnya pada kinerja individu (Cohen, 2006), hal ini didukung juga oleh studi-studi lain yang memperlihatkan hubungan positif antara perbedaan suku dengan tingkat OCB (Donaldson dkk., 2000; Cropanzano dkk., 2003).

Hasil penyusuran data di RSUD Labuang Baji di dapatkan bahwa pada tahun 2017 tingkat kinerja perawat di instalasi rawat inap RSUD Labuang Baji belum maksimal yaitu 76,58 \% dari standar PPNI (Persatuan Perawat Nasional Indonesia) 100\%. Penelitian ini ditujukan untuk menganalisis pengaruh leader member exchange terhadap organizational Citizenship Behavior Perawat Suku Bugis-Makassar di Instalasi Rawat Inap RSUD Labuang Baji.

\section{BAHAN DAN METODE}

\section{Lokasi dan Rancangan}

Penelitian dilakukan di Instalasi Rawat Inap RSUD Labuang Baji Makassar, Sulawesi Selatan. Jenis penelitian yang dilakukan adalah observasional analitik denagn pendekatan cross sectional study..

\section{Populasi dan sampel}

Populasi penelitian ini adalah perawat Instalasi Rawat Inap RSUD Labuang Baji. Sampel sebanyak 98 orang dipilih secara purposive sampling dengan kriteria inklusi yaitu perawat suku Bugis-Makassar.

\section{Metode pengumpulan data}

Data dikumpulkan melalui kuesioner terstruktur yang berisi pernyataan yang harus diisi oleh responden. Pengukuran dilakukan 
Mahmudah, 2020

dengan menggunakan skala rating. Variabel

LMX diiukur melalui 4 dimensi oleh Liden

dan Maslyn (1998): affect, loyalty,contribution, professional respect dengan 12 item menggunakan konsep LMXMDM yang juga dikembangkan oleh Liden dan Maslyn. Dan variabel OCB menggunakan indikator Organ (1988) yang terdiri dari altruism, courtesy, sportmanship, conscientiousness dan civic virtue dengan 24 indikator yang dikembangkan oleh Podsakoff et all (1999).

Analisis data

Data dianalisis menggunakan program SPSS. Untuk melihat pengaruh leader member exchange terhadap organizational citizenship behavior menggunakan uji regresi linear berganda.

\section{HASIL}

\section{Karakteristik Sampel}

Tabel 1 memperlihatkan karakteristik perawat suku Bugis-Makassar di Instalasi Rawat Inap RSUD Labuang Baji, sebagian besar responden berumur antara 26-46 tahun (90,8 \%) yang merupakan umur usia produktif, 91,8 \% responden berjenis kelamin perempuan, 54,1\% responden telah bekerja lebih dari 10 tahun dan status kepegawaian responden penelitian ini $68,4 \%$ telah PNS.

\begin{tabular}{|c|c|c|c|}
\hline & $\begin{array}{l}\text { Distribusi Frekuensi l } \\
\text { Perawat Suku Bugis. } \\
\text { Instalasi Rawat I } \\
\text { Labuang Baji Tahun }\end{array}$ & $\begin{array}{l}\text { Mak } \\
\text { ap } \\
018\end{array}$ & $\begin{array}{l}\text { ar di } \\
\text { SUD }\end{array}$ \\
\hline & Karakteristik & & nlah \\
\hline No & Responden & $\mathrm{n}$ & $\%$ \\
\hline 1 & Umur & & \\
\hline & Remaja ( $\leq 25$ tahun) & 1 & 1 \\
\hline & Dewasa ( $26-45$ tahun) & 89 & 90,8 \\
\hline & Lansia (46 - 65 tahun) & 8 & 8,2 \\
\hline 2 & Jenis Kelamin & & \\
\hline & Laki-Laki & 8 & 8,2 \\
\hline & Perempuan & 90 & 91,8 \\
\hline 3 & Lama Bekerja & & \\
\hline & $1-5$ tahun & 7 & 7,1 \\
\hline & $6-10$ tahun & 38 & 38,8 \\
\hline & $>10$ tahun & 53 & 54,1 \\
\hline 4 & Status Kepegawaian & & \\
\hline & PNS & 67 & 68,4 \\
\hline & Kontrak & 12 & 12,2 \\
\hline & Honorer & 15 & 15,3 \\
\hline & Lainnya & 4 & 4,1 \\
\hline & Total & 98 & 100 \\
\hline
\end{tabular}

\section{Leader Member Exchange- Organizational}

\section{Citizenship Behavior}

Pada tabel 2 hasil uji regresi linear leader member exchange terhadap organizational citizenship behavior, didapatkan nilai $\mathrm{p}$ sebesar $=0,000<0,05$. dan Fhitung $>\mathrm{F}$ tabel. Pada tabel 3 hasil uji regresi linear variabel penelitian (affect, loyalty, contribution dan proffesional respect didapatkan nilai $p$ untuk affect $(0,044<0,05)$; contribution $\quad(0,024<0,05) ; \quad$ proffesional respect $\quad(0,003<0,05) ; \quad$ dan $\quad$ loyalty $(0,083>0,05)$ 
Tabel 2 Hasil Uji Regresi Linear (Coefficients) Variabel Penelitian (LMX) pada Perawat Suku Bugis-Makassar di Instalasi Rawat Inap RSUD

\begin{tabular}{|c|c|c|c|c|c|}
\hline \multirow{2}{*}{ Model } & \multicolumn{2}{|c|}{$\begin{array}{c}\text { Unstandardized } \\
\text { Coefficients }\end{array}$} & \multirow{2}{*}{$\begin{array}{c}\begin{array}{c}\text { Standardized } \\
\text { Coefficients }\end{array} \\
\text { Beta }\end{array}$} & \multirow{2}{*}{$\mathbf{t}$} & \multirow{2}{*}{ Sig. } \\
\hline & B & $\begin{array}{l}\text { Std. } \\
\text { Error }\end{array}$ & & & \\
\hline (Constan) & 43,930 & 7,361 & & 5,968 &, 000 \\
\hline LMX &, 926 & , 186 & 454 & 4,989 &, 000 \\
\hline
\end{tabular}

Tabel 3 Hasil Uji Regresi Linier (Coefficients) Variabel Penelitian (Affect, Loyalty, Contribution, Proffesional Respect) pada Perawat Bugis-Makassar RSUD Labuang Baji Tahun 2018

\begin{tabular}{|c|c|c|c|c|c|}
\hline \multirow{2}{*}{ Model } & \multicolumn{2}{|c|}{$\begin{array}{c}\text { Unstandardized } \\
\text { Coefficients }\end{array}$} & $\begin{array}{c}\text { Standardized } \\
\text { Coefficients }\end{array}$ & \multirow{2}{*}{$\mathbf{t}$} & \multirow{2}{*}{ Sig. } \\
\hline & B & $\begin{array}{l}\text { Std. } \\
\text { Error }\end{array}$ & Beta & & \\
\hline (Constan) & 43,750 & 7,750 & & 5,645 & ,000 \\
\hline Affect &, 881 & ,431 & ,203 & 2,044 & ,044 \\
\hline Loyalty & ,809 & ,462 &, 176 & 1,750 & 083 \\
\hline Contribution & ,995 & ,435 & ,220 & 2,287 & ,024 \\
\hline Proffesional Respect & 1,038 & ,341 & 283 & 3,041 &, 003 \\
\hline
\end{tabular}

\section{PEMBAHASAN}

Penelitian ini menunjukkan bahwa leader member exchange berpengaruh terhadap organizational citizenship behavior perawat suku Bugis-Makassar di instalasi rawat inap RSUD Labuang Baji Makassar. Pembuktian dengan regresi linear antara LMX terhadap OCB memperlihatkan hasil yang positif dan signifikan berpengaruh $(p<0,05)$. Kemudian dengan uji regresi linear berganda didapatkan bahwa ketiga dimensi yaitu proffesional respect, affect, dan contribution memiliki $\mathrm{p}<0,05$ signifikan berpengaruh terhadap OCB, sedangkan loyalty memiliki $\quad \mathrm{p}>0,05 \quad$ yang memperlihatkan tidak signifikan terhadap OCB.

Hasil penelitian yang memperlihatkan adanya pengaruh LMX terhadap OCB sesuai dengan yang dikemukakan oleh Wayne (2002) bahwa kualitas hubungan leader member exchange yang tinggi dapat memotivasi karyawan untuk menunjukkan perilaku OCB (Wayne dkk., 2002). Riggio (1990) juga berpendapat apabila interaksi atasan-bawahan berkualitas tinggi maka seorang atasan akan berpandangan positif terhadap bawahannya sehingga bawahannya akan merasakan bahwa atasannya banyak memberikan dukungan dan motivasi, hal ini 
meningkatkan rasa percaya dan hormat bawahan pada atasannya dengan demikian mereka termotivasi untuk melakukan lebih dari yang diharapkan oleh atasan mereka (Riggio,1990). Hal tersebut sesuai dengan teori pertukaran sosial (social exchange theory), yang mengatakan bahwa leader member exchange dipersepsikan level tinggi oleh karyawan akan membuat mereka "merasa berkewajiban" untuk memberi imbal baliknya (reciprocity).

Melalui analisis regresi linear berganda LMX-Proffesional respect dengan $\mathrm{p}=0,003<0,05$ terhadap OCB dan LMXaffect dengan 0,044 0,05 terhadap OCB. Proffesional respect dan affect terjadi karena interaksi langsung dengan atasan melalui sikap peduli dan perhatian dimana atasan mengamati dan mendengarkan bawahan mereka yang akan meningkatkan rasa hormat sehingga bawahan akan bekerja semaksimal mungkin bahkan dengan sukarela yang menyebabkan peningkatan OCB bawahan (Findley dkk., 2000). Ibrahim (2017) mengatakan bahwa affect dan proffesional respect adalah faktor non kerja yang menunjukkan tingkat rasa hormat yang dimiliki seseorang karena perasaan afeksi/cinta dari bawahan kepada atasannya (Ibrahim dkk., 2017).
LMX-Contribution

dengan $\mathrm{p}=0,024<0,05$ signifikan berpengaruh terhadap OCB. Kontribusi diukur pada upaya dan investasi yang dikontribusikan secara eksplisit dan implisit antara atasan dan bawahan untuk efisiensi operasional organisasi sehingga hal ini menjadikan kontribusi sebagai faktor yang menuntun untuk mencapai kriteria yang tinggi dari OCB (Dienesch dkk., 1986) dan Smith (1983) yang mengatakan OCB sebagai kontribusi yang dilakukan pada saat bekerja diluar dari pekerjaan yang harus dilakukan (Smith,1983).

LMX-loyalty dari hasil analisis regresi linear berganda menunjukkan $\mathrm{p}=$ $0,083>0,05$ artinya tidak ada pengaruh antara loyalty dan OCB. Hal ini berbeda dengan karakter Bugis-Makassar yang dikenal memiliki sikap setia/loyal (marenreng perru).

\section{KESIMPULAN DAN SARAN}

Kami menyimpulkan bahwa terdapat pengaruh pengaruh leader member exchange terhadap organizational citizenship behavior, hasil penelitian responden dengan karakter Bugis-Makassar yang erat dengan nilai budaya siri' na pacce dengan kriteria sipakatau (kemanusiaan); deceng (baik); asseddingeng (kesatuan) dan marenreng perru (setia) menunjukkan bahwa ada 
Mahmudah, 2020

pengaruh signifikan proffesional respect $(\mathrm{p}<0,05)$, contribution $(\mathrm{p}<0,05)$, dan affect $(p<0,05)$ terhadap organizational citizenship behavior. Sebaliknya, tidak ada pengaruh loyalty $(\mathrm{p}>0,05)$ terhadap organizational citizenship behavior perawat Suku Bugis Makassar. Agar performa perawat di Instalasi rawat Inap dapat dipertahankan pimpinan rumah sakit harus memperhatikan kualitas hubungan antara atasan dan bawahan.

\section{DAFTAR PUSTAKA}

Amin, K. F. and Tang, M. R. (2015). 'The Ideology of Buginese in Indonesia ( Study of Culture and Local Wisdom )', 6(4), pp. 758-765.

Anand, S., Vidyarthi, P. and Rolnicki, S. (2017). 'Leader-member exchange and organizational citizenship behaviors: Contextual e ff ects of leader power distance and group task interdependence', The Leadership Quarterly. Elsevier, (September), pp. $1-12$. doi: 10.1016/j.leaqua.2017.11.002.

Cohen, A. (2006). 'The relationship between multiple commitments and organizational citizenship behavior in Arab and Jewish culture', Journal of Vocational Behavior, 69(1), pp. 105118. doi: 10.1016/j.jvb.2005.12.004.

Cropanzano, R., Rupp, D. E. and Byrne, Z. S. (2003). 'The relationship of emotional exhaustion to work attitudes, job performance, and organizational citizenship behaviors', Journal of Applied Psychology, 88(1), pp. 160169. doi: 10.1037/00219010.88.1.160.

Donaldson, S. I. and Ph, D. (2000). 'Longitudinal Examination of
Mentoring Relationships on Organizational Commitment and Citizenship Behavior', 26(4), pp. 233-249.

Findley, H. M., Giles, W. F. and Mossholder, K. W. (2000). 'Performance appraisal process and system facets: Relationships with contextual performance', Journal of Applied Psychology, 85(4), pp. 634-640. doi: 10.1037/0021-9010.85.4.634.

Gooty, J. and Yammarino, F. J. (2013). 'The Leader - Member Exchange Relationship : A Multisource, CrossLevel Investigation', $\mathrm{XX}(\mathrm{X})$, pp. 121. doi: 10.1177/0149206313503009.

Ibrahim, R. M., Ghani, M. A. and Amin, A. (2017). 'International Review of Management and Marketing Does Leader-Member Exchange Impact on Organizational ... Does LeaderMember Exchange Impact on Organizational Citizenship Behaviour Readiness? Evidence from State Government Agency', 7(January), pp. 216-221.

Omar, A. T. and Amat, A. (2017). 'Etika Kerja Etnik Bugis di Sabah: Satu Kajian di Organisasi Awam', (25), pp. 75-86.

Pelras, Christian. (2006). Manusia Bugis. Jakarta :Forum Jakarta Paris.

Podsakoff, P. M., Mackenzie, S. B., Paine, J. B. and Bachrach, D. G. (2000). 'Organizational Citizenship Behaviors: A'. doi: 10.1177/014920630002600307.

Robbins, S. P. (2013). organizational Behavior. 15th edn. PEARSON.

Smith, C. A., Organ, D. W. and Near, J. P. (1983). 'Organizational Citizenship Behavior: Its Nature, Antecedents, and Consequences', Journal of Applied Psychology, (68), pp. 653663.

Taghinezhad, F., Safavi, M., Raiesifar, A. and Yahyavi, S. H. (2015). 'Antecedents 
Mahmudah, 2020

of organizational citizenship behavior among Iranian nurses: a multicenter study', BMC Research Notes. BioMed Central, pp. 1-8. doi: 10.1186/s13104-015-1505-1.

Wayne, S. J., Shore, L. M., Bommer, W. H. and Tetrick, L. E. (2002). 'The Role of Fair Treatment and Rewards in Perceptions of Organizational Support and Leader - Member Exchange', 87(3), pp. 590-598. doi: 10.1037//0021-9010.87.3.590. 